\title{
PSA Level Greater than Five
}

National Cancer Institute

\section{Source}

National Cancer Institute. PSA Level Greater than Five. NCI Thesaurus. Code C136628.

A blood concentration of prostate specific antigen greater than $5 \mathrm{ng} / \mathrm{mL}$. 